\title{
A Study of Bile and Stone in Patient with CalculousCholecystitis
}

\author{
DrAbidAli.K.P ${ }^{1}$,Dr Prasad Paul ${ }^{2}$, Dr Monish ${ }^{3}$,Dr Sarvotaman Nedungadi ${ }^{4}$ \\ 1.Associate professor Department of general surgery MES medical college .Perintalmanna \\ 2.Assistant professor Department of general surgery MES medical college .Perintalmanna \\ 3. Senior resident Department of general surgery MES medical college .Perintalmanna \\ 4.Professor Department of general surgery MES medical college .Perintalmanna
}

\begin{abstract}
Cholelithiasis is a major problem worldwide now and its incidence increased rapidly in recent years and also the various newer surgical modalities are now available for the treatment of gall stones. The main factor for the increased incidence is found to be change in lifestyle and appearance of newer imaging techniques.In our studies we mainly focusing on the type of stone in our population and some of the risk factors for stone development. We are also studying here the type of organism and the antibiotic sensitivity pattern also in patient with symptomatic cholelithiasis
\end{abstract}

Keywords: Cholelithiasis,choledocholithiasis,bactibilia,diabetesmellitus,klebsiella,obstructive jaundice

\section{Introduction}

Calculus disease of the biliary tract continues to be a significant international problem(1). There is a significant increase in the incidence of gallbladder disease during the past ten years. This may be due to the change in the dietary habit with the introduction of refined oil,pre cooked and bottled food materials that are being increasingly used. Another reason may be the increased detection of the gall stones with the introduction of newer imaging technologies. Gall stone disease may acquire a wide range of clinical presentations ranging from asymptomatic gallstones to an emergency surgical situation resulting from perforation and biliary peritonitis occurring in acute cholecystitis(2-5).Significant advances have occurred in our understanding of the physiochemical relationship of the biliarylipids providing insights in to the mechanism of gall stone formation but regarding the formation of pigment stones our knowledge is very limited. The incidence of infection in cholelithiasis is ranging from $10 \%$ in normally functioning gall bladder with stones to $80 \%$ in choledocholithisis.But it is not well established whether infection predisposes to gall stones, or stone predisposes to infection. Recent studies have shown that infection is a major cause for the development of brown pigment stones(6).

\section{Objectives Of Study}

1. To find out the type of gallstones in cholelithiasis

2. To find out the bacteriology of the biliary tract.

3. To find out the incidence of bactobilia in cholelia in cholelithiasis.

4. To study the antibiotic sensitivity pattern of the organisms.

5. To study the risk factors associated with bactobilia in cholelithiasis.

\section{Materials And Methods}

64 patients presented with chronic calculouscholecystitis, proved by ultra sound scanning, during a period of 3 years from 2009 - 2013 were studied. Patients presented with acute calculous cholecystitis and acalculous cholecystitis were excluded. Patients were evaluated for risk factors associated with bactibilia. Risk factors evaluated include diabetic mellitus, age and jaundice.

At operation, aeorobic culture of bile was obtained by direct puncture of the gall bladder. Aerobic culture of bile was also obtained from CBD, in those who have undergone CBD exploration. Bile was analysed for chemical composition. Bile from patients why underwent surgery for rather conditions were used as controls. Gall stones obtained were analyzed for chemical compositions. Statistical analyses of the data were done by X2 test. 
IV. Observation

THE TYPE OF STONE IN CHOLELITHIASIS

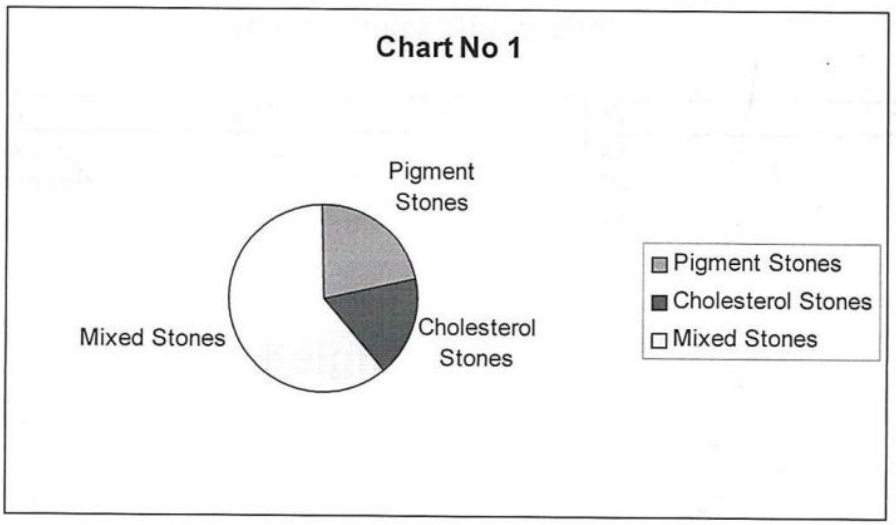

INCIDENCE OF BACTIBILIA

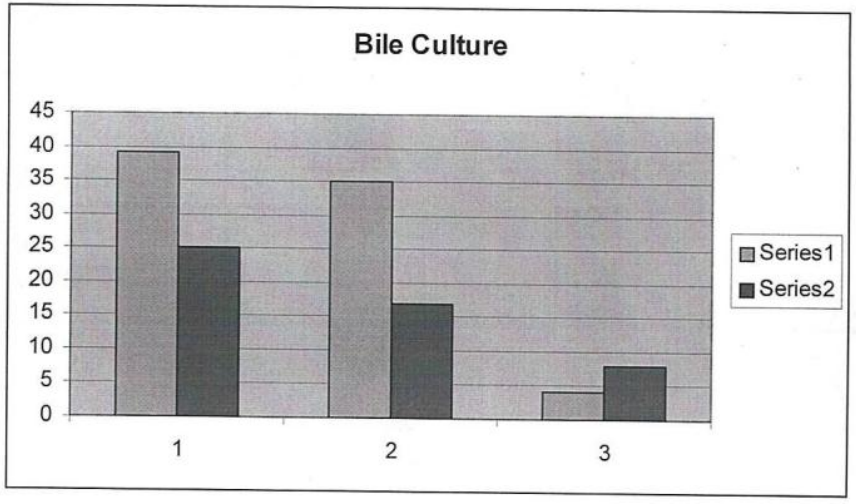

Total No. of Patients

$=$

Number of patients with bactibilia $=25$

Number of patients with GB Stone alone $=52$

Culture positive

Number of patients with CBD Stone

Culture positive

64

$=17$

$=12$

$=08$

Bacteriology of the biliary tract

Present Study (Perinthalmanna)

\begin{tabular}{|l|l|l|}
\hline Bacterium & No. & $\%$ \\
\hline Klebsiella & 12 & 48 \\
Escherichia coli & 7 & 28 \\
Entero cocci & 4 & 16 \\
Strepto cocci & 2 & 8 \\
\hline
\end{tabular}

Keighley, 1977

\begin{tabular}{|c|c|c|}
\hline Bacteria & No. & $\%$ \\
\hline $\begin{array}{l}\text { Aerabic } \\
\text { Gram positive }\end{array}$ & & \\
\hline $\begin{array}{l}\text { Streptococcus faecalis } \\
\text { Viridans streptococi }\end{array}$ & 51 & 14.78 \\
\hline $\begin{array}{l}\text { Viridans streptococci } \\
\text { Others }\end{array}$ & $\begin{array}{l}12 \\
8\end{array}$ & $\begin{array}{l}3.18 \\
2.32\end{array}$ \\
\hline $\begin{array}{l}\text { Gram negative } \\
\text { Escherichia coli }\end{array}$ & 127 & 36.81 \\
\hline Klebsiella & 36 & 10.43 \\
\hline $\begin{array}{l}\text { Others } \\
\text { Anaerobic }\end{array}$ & 48 & 13.91 \\
\hline $\begin{array}{l}\text { Gram positive } \\
\text { Clostridium perfringens }\end{array}$ & & \\
\hline $\begin{array}{l}\text { Costridium pertringens } \\
\text { Others }\end{array}$ & 23 & $\begin{array}{l}8.41 \\
6.67\end{array}$ \\
\hline $\begin{array}{l}\text { Gram negative } \\
\text { Bacteroids fragilis }\end{array}$ & 6 & 1.74 \\
\hline Others & 5 & \\
\hline
\end{tabular}

Antibiotic sensitive pattern

\begin{tabular}{|l|l|l|l|l|}
\hline \multirow{2}{*}{ Bacteria } & \multicolumn{4}{|l|}{ Antibiotic } \\
\cline { 2 - 5 } & AMP & CEPH & GENTA & TETRA \\
\hline Klebsiella & - & + & + & + \\
Escherichia coli & - & & & + \\
Entero cocci & - & & & + \\
Strepto cocci & - & & & + \\
\hline
\end{tabular}


RISK FACTORS AND BACTIBILIA

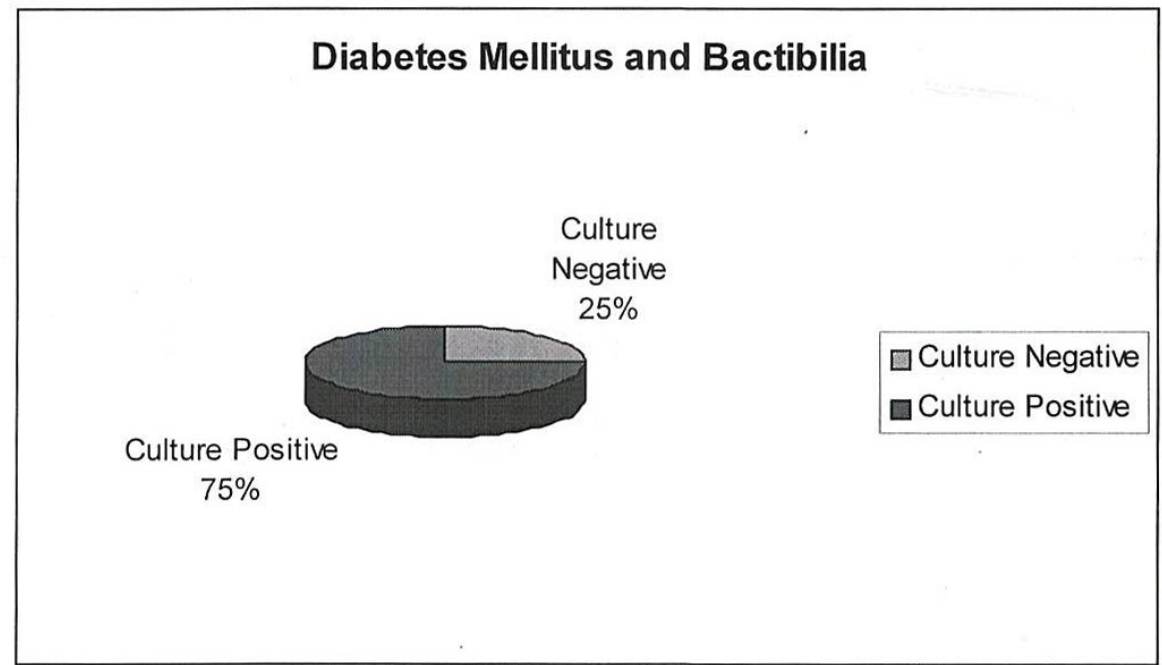

Total Number of Diabetes

$=8$

Culture Positive

$=6$

$\mathrm{P}<0.05$

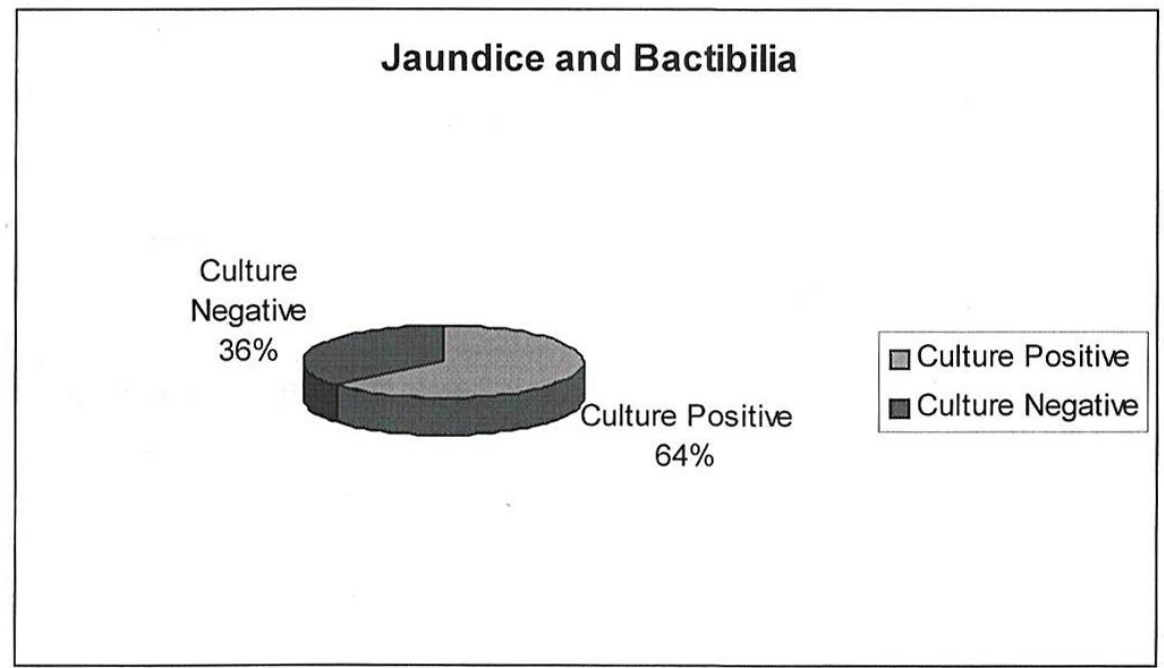

Total Number of Patients with Jaundice

$=11$

Culture Positive

$=07$

$\mathrm{P}>0.05$ 


\section{Choledocholithiasis and Bactibilia}

Culture Negative $33 \%$

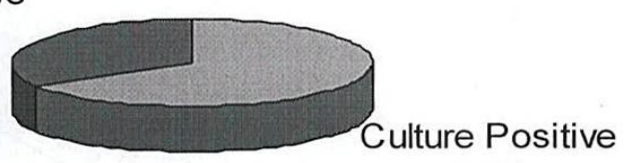

$67 \%$

Total Number of Patients with CBD Stone $=12$

Culture Positive

$=08$

$\mathrm{P}>0.1$ 


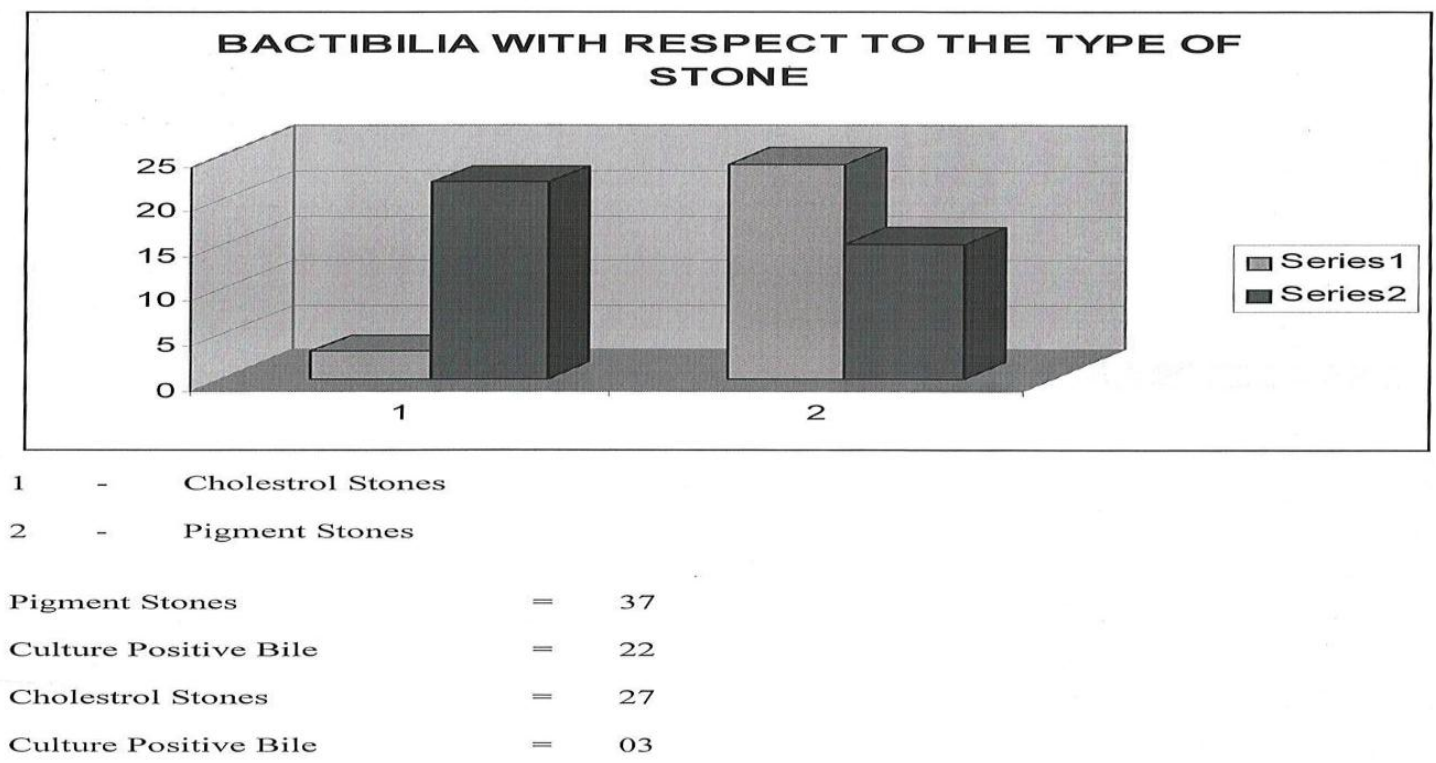

\section{Discussion}

A total of 64 patients who presented chronic calculus cholecystitis admitted in Medical college Hospital, perintalmanna during 2009 - 2013 were taken for this study.

\subsection{THE TYPE OF STONE IN CHOLELITHIASIS}

It was found that 52 patients had gall bladder stone alone and 12 patients had both gall bladder and CBD Stone. This is comparable to many western series which shows an incidence of CBD Stones varying from $6-19.5 \%$. Biochemical analysis of the stone showed 37 had mixed stone and $15 \%$ had cholestrol stone and $13 \%$ pigment stone. This division is based on predominant constituent of each sample of stone. The comparative incidence in western series is pigment stones $25 \%$ and cholestrol stones $75 \%$. (7-9)

\subsection{BACTERIOLOGY THE BILIARY TRACT (TABLE NO. II \& III)}

Bacteria found in the bile are those that found in the distal ileum and colon. Organisms isolated in this study in the descending order of frequency were Klebsiella (48\%), Escherichia Coli (28\%), Enterococci (16\%) and streptococci $(8 \%)$. In literature gram negative aerobes are present in about two thirds $(65 \%)$ of patients with positive bile culutures (79\%). Escherichia Coli is the most common species (50\% of isolates), followed by Klebsiella. Other less common gram negative aerobes are Enterobacter, Protieus and Pseudomonas. Gram positive aerobes are found in apporximately on e - third (35\%) of positive cultures and the most common organism is streptococcus faecalis. Other gram positive organisms include Streptococcus viridians and Staphylococusaureus. Anaerobes have been found with increasing frequency in bile cultures as anaerobic culture media and transport mechanism improved. Recent studies demonstrate anaerobes in 20-40\%) of patients with positive bile cultures. The most frequently isolated anaerobe is Bacteriodesfragilis, a gram negative organism. Aerobes alone can be found in upto $60 \%$ of isolates, both aerobes and anaerobes in upto $40 \%$ and anaerobes alone in upto $5 \%$ of cases. 


\subsection{ANTIBIOTIC SENSITIVITY OF THE ORGANISMS}

All the bacterial isolates in this study except Streptococci were resistant to Ampicillin.All the organisms were sensitive to cephalosporins, Aminoglycosides and Tetracyclin (Table No.IV).

Gram negative aerobes are the main target of anibiotic prophylaxis. Aminoglycosides are effective against E.coli, Klebsiella and Proteus. First generation cephalosporins (Cefazolin and Cephalothin) are effective against E.coli, Klebsiella, and Proteus, and because of low toxicity and cost are the drugs of choice for prophylactic use. Second generation cephalosporins (Cefoxitin, Cefamandole) have more activity against gram negative aerobes. Third - generation cephalosporins (cefotaxime, moxalactam) have even greater gram negative activity, but resistant strains develop with more frequency. The newer pencillins (azlocillin, mezlocillin, piperacillin, and ticarcillin) are effective against many gram negative organisms.

The most common gram positive aerobe, enterococcus, is best covered by Ampicillin or Penicillin G in combination with an Amnioglycoside. Metronidazole is the drug of choice for anaerobic bacteria. It has the most complete coverage against nearly all anaerobic bacteria, is relatively free of against nearly all anaerobic bacteria, is relatively free of toxic effects, and is not very expensive. Clindamycin is the second drug of choice, because although it is as effective, it has greater toxicity and is more expensive.

For prophylaxis only it is sufficient to cover for the more common gram negative aerobes Hence a combination of cephalosporin and an aminoglycoside can cover majority of the organisms in the bile.(18-23)

\subsection{RISKS FACTORS AND BACTIBILIA}

It has been found that certain factors are associated with high incidence of bactibilia. Risk factors evaluated in this study include DiabetisMelitus, obstructive jaundice and age.

\subsection{DIABETES MELLITUS AND BACTIBILIA}

This study showed that Diabetes is associated with high incidence of bactibilia (Chart No.III). Of the 8 diabetic patients with gall stones, $6(75 \%)$ had infected bile. This is found to be statistically significant $(\mathrm{P}<$ $0.05) .(10-17)$

\subsection{OBSTRUCTIVE JAUNDICE AND BACTIBILIA}

Obstructive jaundice patients are at risk for high incidence of bactibilia. This is especially so when the obstruction is due to stones or benign strictures.Of the 12 patients with CBD stone, 11 patients had obstructive jaundice. Among these 7 (63.6\%) patients had infected bile (Chart No.IV). This shows that patients with obstructive jaundice due to stones are at high risk for bactibilia. In several series, the incidence of bactibilia in patients with obstructive jaundice due to stones varies from $50 \%$ to $100 \%$. One patient in this study without jaundice had sterile bile.

\subsection{CHOLEDOCHOLITHIASIS AND BACTIBILIA}

Choledocholithiasis is also associated with a high incidence of bactibilia (Chart No. VI). In this study incidence of bactibilia was $32.1 \%$ in patients without common bile duct stones. In patients with CBD stone the infection rate was 66\%.Patients with pigment stones had high incidence of bactibilia when compared to patients with cholesterol stone (Chart No VII). This suggests a probable aetiological role of infection in the development of pigment stones(7-9).

\section{Conclusion}

1. This study showed that majority of our patients has mixed stones in contrast to cholesterol stones in Western population.

2. Bactibilia is a common association in gall stone disease.

3. Klebsiella is the commonest organism in this study, in contrast to E.coli in literature.

4. Majority of the organisms are sensitive to cephalosporins and aminoglycoside antibiotics. Hence these drugs could be used in the prophylaxis of biliary surgery.

5. Diabetics are associated with high incidence of bactibilia.

6. Bactibilia in gall stone disease increases as age advances.

7. Obstructive jaundice due to choledocholithiasis is associated with incidence of bactibilia

\section{References}

[1]. Bodmer M, Brauchli YB, Krahenbuhl S, Jick SS, Meier CR: Statin use and riskof gallstone disease followed by cholecystectomy. JAMA 2009,302(18):2001-2007.

[2]. Guss DA, Oyama LC: Disorders of the Liver and Biliary Tract. In Rosen'sEmergency Medicine: Concepts and Clinical Practice.. 7 edition. Edited by:John Marx RH, Ron Walls. Philadelphia: Mosby; 2010:

[3]. Meshikhes AW: Asymptomatic gallstones in the laparoscopic era. J R CollSurgEdinb 2002, 47(6):742-748

[4]. Ayantunde AA, Agrawal A: Gallstone ileus: diagnosis and management.World J Surg 2007, 31(6):1292-1297. 
[5]. Gasparrini M, Liverani A, Catracchia V, Conte S, Leonardo G, Marino G,Milillo A, Mari FS, Pezzatini M, Favi F: Gallstone ileus: a case report andreview of the literature. ChirItal 2008, 60(5):755-759.

[6]. Portincasa P, Moschetta A, Palasciano G: Cholesterol gallstone disease.Lancet 2006, 368(9531):230-239

[7]. Ho KJ, Lin XZ, Yu SC, Chen JS, Wu CZ: Cholelithiasis in Taiwan. Gallstonecharacteristics, surgical incidence, bile lipid composition, and role ofbeta-glucuronidase. Dig Dis Sci 1995, 40(9):1963-1973.

[8]. Tazuma S: Gallstone disease: Epidemiology, pathogenesis, andclassification of biliary stones (common bile duct and intrahepatic). BestPract Res ClinGastroenterol 2006, 20(6):1075-1083.

[9]. Yoo EH, Oh HJ, Lee SY: Gallstone analysis using Fourier transforminfrared spectroscopy (FT-IR). ClinChem Lab Med 2008, 46(3):376-381

[10]. Liu CM, Tung TH, Liu JH, Lee WL, Chou P: A community-basedepidemiologic study on gallstone disease among type 2 diabetics inKinmen, Taiwan. Dig Dis 2004, 22(1):87-91.

[11]. Chen CH, Huang MH, Yang JC, Nien CK, Etheredge GD, Yang CC, YehYH,Wu HS, Chou DA, Yueh SK: Prevalence and risk factors of gallstonedisease in an adult population of Taiwan: an epidemiological survey. JGastroenterolHepatol 2006, 21(11):17371743.

[12]. Chen CY, Lu CL, Lee PC, Wang SS, Chang FY, Lee SD: The risk factors forgallstone disease among senior citizens: an Oriental study.Hepatogastroenterology 1999, 46(27):1607-1612

[13]. Tung TH, Ho HM, Shih HC, Chou P, Liu JH, Chen VT, Chan DC, Liu CM: Apopulation-based follow-up study on gallstone disease among type 2diabetics in Kinmen, Taiwan. World J Gastroenterol 2006, 12(28):4536-4540.

[14]. Liu CM, Tung TH, Chou P, Chen VT, Hsu CT, Chien WS, Lin YT, Lu HF, Shih HC, Liu JH: Clinical correlation of gallstone disease in a Chinesepopulation in Taiwan: experience at Cheng Hsin General Hospital. WorldJGastroenterol 2006, 12(8):12811286.

[15]. Lu SN, Chang WY, Wang LY, Hsieh MY, Chuang WL, Chen SC, Su WP, Tai TY,Wu MM, Chen CJ: Risk factors for gallstones among Chinese in Taiwan. Acommunitysonographic survey. J ClinGastroenterol 1990, 12(5):542-546.

[16]. Chen CY, Lu CL, Huang YS, Tam TN, Chao Y, Chang FY, Lee SD: Age is oneof the risk factors in developing gallstone disease in Taiwan. Age Ageing1998, 27(4):437-441.

[17]. Acalovschi M: Cholesterol gallstones: from epidemiology to prevention.Postgrad Med J 2001, 77(906):221-229.

[18]. Yellin AE, Berne TV, Appleman MD: A randomized study ofcefepime versus the combination of gentamicin and mezlocillinas an adjunct to surgical treatment in patients with acutecholecystitis.SurgGynecolObstet 1993, 177:23-29.

[19]. Krajden S, Yaman M, Fuksa M: Piperacillin versus cefazolin givenperioperatively to high-risk patients who undergo opencholecystectomy: a double-blind, randomized trial.Can J Surg 1993, 36:245-250.

[20]. Karachalios GN, Nasiopoulou DD, Bourlinou PK, Reppa A:Treatment of acute biliary tract infections with ofloxacin: arandomized, controlled clinical trial.Int J ClinPharmacolTher 1996, 34:555-557.

[21]. Lee W, Chang K, Lee C: Surgery in cholangitis: bacteriology andchoice of antibiotic.Hepatogastro-enterology 1992, 39:347.

[22]. Thompson JE, Bennion RS, Roettger R: Cefepime for infections ofthe biliary tract.SurgGynecolObstet 1993, 177:30-34.

[23]. Gerecht W, Henry N, Hoffman W: Prospective randomizedcomparison of mezlocillin therapy alone with combinedampicillin and gentamicin therapy for patients with cholangitis.Arch Intern Med 1989, 149:1279-1284. 